Proceeding Paper

\title{
New Dibenzofuran Compounds Obtained by Dihydrousnic Acid Hydrogenation ${ }^{+}$
}

\author{
Aleksandr Filimonov*, Olga Luzina and Nariman Salakhutdinov \\ N. N. Vorozhtsov Novosibirsk Institute of Organic Chemistry, Siberian Branch of the Russian Academy of \\ Sciences, 9, Akademika Lavrentieva Ave., 630090 Novosibirsk, Russia; luzina@nioch.nsc.ru (O.L.); \\ anvar@nioch.nsc.ru (N.S.) \\ * Correspondence: alfil@nioch.nsc.ru; Tel.: +7-913-008-08-02 \\ + Presented at the 24th International Electronic Conference on Synthetic Organic Chemistry, \\ 15 November-15 December 2020; Available online: https://ecsoc-24.sciforum.net/.
}

Citation: Filimonov, A.; Luzina, O.; Salakhutdinov, N. New

Dibenzofuran Compounds Obtained by Dihydrousnic Acid

Hydrogenation. Chem. Proc. 2021, 3 , 21. https://doi.org/10.3390/ecsoc-2408460

Academic Editors: Julio A. Seijas and M. Pilar Vázquez-Tato

Published: 16 November 2020

Publisher's Note: MDPI stays neutral with regard to jurisdictional claims in published maps and institutional affiliations.

Copyright: $@ 2020$ by the authors. Licensee MDPI, Basel, Switzerland. This article is an open access article distributed under the terms and conditions of the Creative Commons Attribution (CC BY) license (http://creativecommons.org/licenses/by/4.0/).

\begin{abstract}
It has been found that usnic acid carbonyl groups can be hydrogenated by the action of
\end{abstract} $\mathrm{H}_{2} / \mathrm{Pd}(\mathrm{C})$. Thus, two new dibenzofuran derivatives were synthesized.

Keywords: usnic acid; hydrogenation

\section{Introduction}

(+)-Usnic acid (1) is a commercially available lichen metabolite. Its biological activity is diverse, from antibacterial and anticancer to immunomodulating [1]. Its biological properties, as well as broad occurrence in various lichen species and high optical purity of the isolated product make it promising as a base for developing novel pharmaceuticals.

Earlier it was shown that the interaction of (+)-usnic acid 1 with reducing agents occurs along the $\mathrm{C}$ ring of the dibenzofuran core. The reaction proceeds under the action of $\mathrm{H}_{2} / \mathrm{Pd}(\mathrm{C})$ through the reduction of the C4-C4a double bond with the formation of dihydrousnic acid 2, or under the action of sodium borohydride through the reduction of $\mathrm{C} 1=\mathrm{O}$ and $\mathrm{C} 11=\mathrm{O}$ carbonyl groups to hydroxyl groups with the formation of a mixture of diastereomeric compounds 3 (Scheme 1) [2].<smiles>CC(=O)C1=C(O)C[C@@H]2Oc3c(C(C)=O)c(O)c(C)c(O)c3[C@H]2C1=O</smiles>

2- Dihydrousnic acid
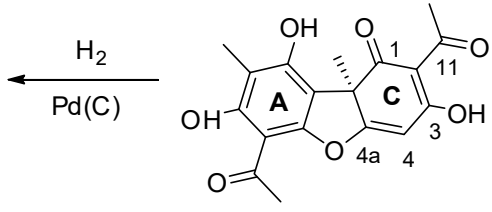

1 - (+)-Usnic acid<smiles>CC(=O)c1c(O)c(C)c(O)c2c1OC1=CC(O)=C([18OH])[C@@H](C)[C@H]1[C@@H]2O</smiles>

Scheme 1. Hydrogenation of usnic acid with different reagents.

We found that further hydrogenation of dihydrousnic acid in $\mathrm{H}_{2} / \mathrm{Pd}(\mathrm{C})$ led to two new products.

\section{Results and Discussion}

The hydrogenation was carried out in tetrahydrofuran (THF) at room temperature and atmospheric pressure. Based on the ${ }^{13} \mathrm{C}$ and ${ }^{1} \mathrm{H}$ NMR spectra, the reaction proceeds in ring $\mathrm{C}$, since the signals related to the atoms of ring $\mathrm{A}$ remain unchanged. The position of the signals in the ${ }^{1} \mathrm{H}$ and ${ }^{13} \mathrm{C}$ spectra for $\mathrm{CH}(4 \mathrm{a})$ also remained unchanged, which indicates that the furan ring remains closed. Consequently, the carbonyl groups of ring $\mathrm{C}$ were 
subjected to reduction. For each of the products, reduction of only one of the three carbonyl groups of ring $C$ was observed. Hydrogenation of $\beta$-diketone systems under similar conditions is known in the literature [3,4]. The reduction of carbonyl groups in this case occurs with the formation of methylene groups (Scheme 2).

In the first product spectra, characteristic signals for the ethyl fragment were found, which indicates that the reduction in this case occurred at the exocyclic carbonyl group. In the second product spectra, a shift of the $\mathrm{C} 4$ signal of the methylene group towards strong field and an increase in the multiplicity of this signal due to the appearance of another methylene group nearby were observed. Therefore, reduction of the $\mathrm{C} 3=\mathrm{O}$ carbonyl group took place.<smiles>CC(=O)C1=C(O)C[C@H]2Oc3c(C(C)=O)c(O)c(C)c(O)c3[C@]2(C)C1=O</smiles>

\section{2- Dihydrousnic acid}

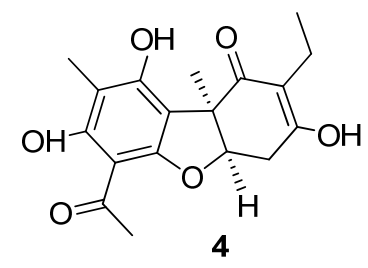

4

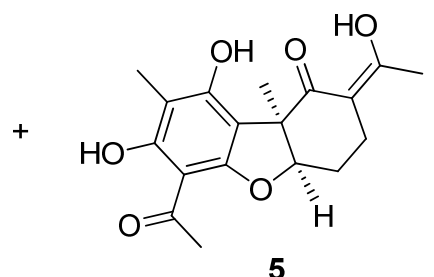

5

Scheme 2. Hydrogenation of dihydrousnic acid.

\section{Materials and Methods}

\subsection{Methods}

Reagent-grade solvents were redistilled prior to use. Synthetic starting materials, reagents, and solvents were purchased from Sigma-Aldrich, Acros Organics. Dihydrousnic acid 2 was obtained by hydrogenation as described [5].

The analytical and spectral studies were conducted at the Chemical Service Center for the collective use of the Siberian Branch of the Russian Academy of Science.

The ${ }^{1} \mathrm{H}$ and ${ }^{13} \mathrm{C}-\mathrm{NMR}$ spectra for solutions of the compounds in $\mathrm{CDCl}_{3}$ were recorded on a Bruker AV-400 spectrometer (400.13 and $100.61 \mathrm{MHz}$, respectively). The residual signals of the solvent were used as references $\left(\delta_{\mathrm{H}} 2.48\right.$, $\delta$ с 39.52 for DMSO- $\mathrm{d}_{6}$ and $\delta_{\mathrm{H}} 7.27, \delta \mathrm{c}$ 77.1 for $\left.\mathrm{CDCl}_{3}\right)$. Merck silica gel $(63-200 \mu)$ was used for the column chromatography. Thin-layer chromatography was performed on TLC Silica gel 60F254 (Merck KGaA, Darmstadt, Germany).

\section{Hydrogenation of Dihydrousnic Acid}

Dihydrousnic acid ( $2 \mathrm{~g}$ ) was added to $25 \mathrm{~mL}$ of THF. After the substance dissolved, a catalyst was added to the mixture. A three-way crane was placed on the flask. One output was connected to hydrogen, the other to a vacuum pump. The air from the flask was removed by vacuum. Then the system was filled with hydrogen and stirred for $5 \mathrm{~min}$. The procedure was repeated once. The obtained mixture was stirred in the hydrogen atmosphere overnight. After that, the mixture was filtered off and the solvent was removed. The products were isolated after column chromatography.

(2R,7R)-10-acetyl-4-ethyl-5,11,13-trihydroxy-2,12-dimethyl-8-oxatricyclo[7.4.0.02,7]trideca1(13), 4,9,11-tetraen-3-one (4): Yellow amorphous powder. Yield: $36 \%$. $\delta_{\mathrm{H}}\left(\mathrm{CDCl}_{3}, \mathrm{~J} \mathrm{~Hz}\right)$ : $0.95(3 \mathrm{H}, \mathrm{t}, J=7.5), 1.59(3 \mathrm{H}, \mathrm{s}), 2.01(3 \mathrm{H}, \mathrm{s}), 2.27\left(1 \mathrm{H}, \mathrm{dq}, J_{1}=7.5, J_{2}=7.0\right), 2.33\left(1 \mathrm{H}, \mathrm{dq}, J_{1}=\right.$ $\left.7.5, J_{2}=7.0\right), 2.55(3 \mathrm{H}, \mathrm{s}), 2.89\left(1 \mathrm{H}, \mathrm{dd}, J_{1}=6.0, J_{2}=17.6\right)$ and $2.99\left(1 \mathrm{H}, \mathrm{dd}, J_{1}=6.0, J_{2}=17.6\right)$ (AB-system), $4.83\left(1 \mathrm{H}, \mathrm{dd}, J_{1}=6.0, J_{2}=6.0\right), 9.63(1 \mathrm{H}, \mathrm{ss}), 13.35(1 \mathrm{H}, \mathrm{s}) . \delta \mathrm{c}\left(\mathrm{CDCl}_{3}\right): 7.14$, $12.77,15.44,23.89,31.11,31.90,51.77,84.75,101.67,105.84,106.05,116.92,159.19,159.70$, $162.95,170.0,198.3,201.89$.

(2R,4E,7R)-10-acetyl-11,13-dihydroxy-4-(1-hydroxyethylidene)-2,12-dimethyl-8-oxatricyclo [7.4.0.02,7] trideca-1(13),9,11-trien-3-one (5): Yellow amorphous powder. Yield: $15 \%$. ठн $\left(\mathrm{CDCl}_{3}, \mathrm{~J} \mathrm{~Hz}\right): 1.59(3 \mathrm{H}, \mathrm{s}), 1.99(3 \mathrm{H}, \mathrm{s}), 1.99-2.07(2 \mathrm{H}, \mathrm{m}), 2.28-2.40(1 \mathrm{H}, \mathrm{m}), 2.34(1 \mathrm{H}, \mathrm{ddd}$, 
$\left.J_{1}=4.8, J_{2}=7.0, J_{3}=15.0\right)$ and $2.48\left(1 \mathrm{H}, \mathrm{ddd}, J_{1}=4.8, J_{2}=7.0, J_{3}=15.0\right)($ AB-system $), 2.55(3 \mathrm{H}$, s), $4.69\left(1 \mathrm{H}, \mathrm{dd}, J_{1}=4.6, J_{2}=6.9\right), 9.38(1 \mathrm{H}, \mathrm{s}), 13.42(1 \mathrm{H}, \mathrm{s}), 16.47(1 \mathrm{H}, \mathrm{s}) . \delta \mathrm{c}\left(\mathrm{CDCl}_{3}\right): 8.05$, $20.2,22.90,25.20,27.05,32.24,52.67,89.89,102.62,106.42,106.64,106.70,160.02,160.07$, $164.04,191.74,195.06,202.47$.

\section{Conclusions}

Two new compounds based on usnic acid were obtained. The triketone system of the $\mathrm{C}$ ring in the new compounds is destroyed, which should contribute to the loss of protonophore properties responsible for the toxicity of the native compound. This feature allows the synthesized compounds to be considered as promising platforms for creating new biologically active compounds with increased safety.

Author Contributions: Conceptualization, Data curation, Synthetic investigation, Writing-original draft, and review and editing, O.L. and A.F.; Supervision: N.S. All authors have read and agreed to the published version of the manuscript.

Institutional Review Board Statement: Not applicable.

Informed Consent Statement: Not applicable.

Data Availability Statement: Data available on request.

Funding: This study was funded by the Russian State funded budget project (AAAA-A18118020290188-2).

Acknowledgments: Authors would like to acknowledge the Multi-Access Chemical Research Center SB RAS for spectral and analytical measurements.

Conflicts of Interest: The authors declare no conflict of interest.

\section{References}

1. Luzina, O.A.; Salakhutdinov, N.F. Biological Activity of Usnic Acid and its Derivatives: Part 2. Effects on higher organisms. Molecular and physicochemical aspects. Russ. J. Bioorg. Chem. 2016, 42, 249-268.

2. Sokolov, D.N.; Luzina, O.A.; Salakhutdinov, N.F. Synthesis of ethers of (+)-usninic acid pyrazole derivatives. Chem. Nat. Compd. 2012, 48, 379-384.

3. Bacqué, E.; Paris, J.-M. A Convenient Synthesis of 2,2-Diphenyl-Cyclohexanone and 6,6-Diphenyl-2-Cyclohexen-One. Synth. Comm. 1992, 22, 2259-2272.

4. Toyota, M.; Seishi, T.; Fukumoto, K. Stemodin synthesis (II) - Highly diastereoselective formal total synthesis of -Stemodin via Pd2+-promoted cycloalkenylation reaction. Tetrahedron 1994, 50, 3673-3686.

5. Shibata, S.; Takahashi, K.; Tanaka, Y. Decomposition of Usnic Acid. V. Pyrolysis of Dihydrousnic Acid. (2). Some observations on ihydrousnic acid. Pharm Bull. 1956, 4, 65-67. 